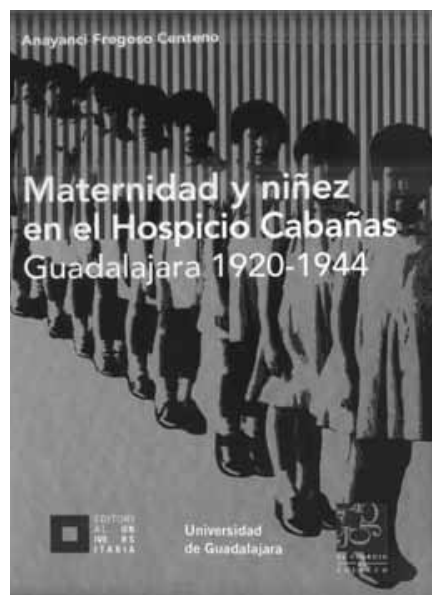

The Production of Good Children and Devoted Mothers in the Making of a Nation

DUCANGE MÉdOR Instituto Tecnológico y de Estudios Superiores de Occidente, Guadalajara, Jalisco, México dmedor@yahoo.com

Desacatos 46, septiembre-diciembre 2014, pp. 216-219
- Maternidad y niñez en el Hospicio

Cabañas. Guadalajara 1920-1944

Anayanci Fregoso Centeno, 2011

Universidad de Guadalajara, El Colegio

de Jalisco, Guadalajara, 356 pp.

\section{La producción de niños buenos y madres devotas en la fabricación de una nación}

\author{
DUCANGE MÉDOR
}

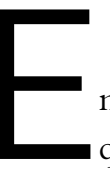

n la historia de Occidente se han documentado numerosos casos que evidencian a menudo que para las autoridades civiles y eclesiales haber parido a un bebé no era motivo suficiente para que se le reconociera a una mujer el derecho de desempeñar los roles social y biológicamente ligados a la maternidad: amamantar, cuidar, criar, proteger, etc. (Kertzer, 1993). El derecho de las progenitoras para ejercer de madres estaba ligado a propiedades de orden moral — ser una "buena" mujer y madre, por ejemplo, estar civil y religiosamente casada, dedicada de tiempo completo a la atención de sus hijos y totalmente sometida a la autoridad de su marido - y en menor medida económico. ${ }^{1}$ Así, durante varios siglos y en varios países europeos, el Estado — con la decidida e interesada colaboración de la Iglesia católica — tenía la potestad de negar

Desde luego, las propiedades de índole económica o material eran atribuidas a las mujeres de manera indirecta, dado que una "buena" madre debía abstenerse de tener un trabajo remunerado fuera de casa, su supervivencia material -y la de sus hijos- dependía completamente de los ingresos de un marido (Pahl, 1984). 
a ciertas mujeres la posibilidad de criar a sus hijos toda vez que, de acuerdo con criterios de rectitud moral o de "normalidad" social, eran consideradas no aptas para educar a un niño o una niña.

Estas prácticas estatales y eclesiales revelan un dato fundamental relativo a una creencia medular de las sociedades en las que han ocurrido: la maternidad, así como la niñez, no es un hecho meramente biológico sino, ante todo, una "construcción social" producto de representaciones, valores, ideas y prácticas sociocultural e históricamente situadas concernientes al ejercicio correcto de la maternidad y a la formación o educación idónea de la niñez (Boch y Thane, 1996). Todo esto de conformidad con el ideal de sociedad o de país que los grupos política y socialmente dominantes buscan propagar. Anayanci Fregoso Centeno se empeña en escudriñar los dispositivos discursivos y las prácticas que fueron orquestados en el Hospicio Cabañas ${ }^{2}$ en torno a la niñez y en alguna medida a la maternidad desde su creación en la primera década del siglo XIX hasta los años cuarenta del siglo pasado.

A lo largo del trabajo, la autora recurre a menudo a conceptos como los de "representación social", "construcción social de la niñez"y de "maternidad" y a la noción un tanto críptica de "orden discursivo de género"3 para exponer y analizar las percepciones, las creencias, las prácticas y los discursos relativos a la maternidad y la niñez en los periodos históricos que abarca su investigación. Se trata de una obra netamente histórica, que se apoya en el análisis de género y en perspectivas conceptuales de corte socioantropológico para, a partir de una revisión de fuentes periodísticas y de documentos oficiales de la época estudiada, dar razón de los gestos, los dispositivos, las alianzas, las acciones políticas y cívicas que establecieron o generaron actores tan diversos como gobernantes, jerarcas eclesiásticos, empresarios y miembros de asociaciones filantrópicas en torno a la maternidad y la niñez en general y en particular a la asilada en el Hospicio Cabañas.
La obra se articula alrededor de dos etapas: la primera va de la fundación del Hospicio a principios del siglo XIX hasta la época de la Revolución Mexicana y la segunda corresponde a la época posrevolucionaria y los inicios de la década de 1940. En uno y otro periodo, la autora establece una estrecha relación entre la misión encargada a la institución y, por un lado, las ideas entonces imperantes en torno a las expectativas y destinos marcados para los individuos con arreglo a su sexo y, por el otro, la necesidad acuciante de forjar el país o la nación mediante la "producción", desde la infancia, de hombres y mujeres idóneos, esto es, conforme a las prescripciones y/o el destino que el entramado de género les asignaba a ellos y a ellas. En palabras de la autora:

la niñez era formada según la construcción de género de la época, de la Iglesia católica y del Estado, que pensaba a los varones como futuros proveedores familiares y productores sociales, y a las mujeres como esposas reproductoras biológicas, como futuras madres y cuidadoras del espacio privado que no precisaban de instrucción formal alguna para desempeñarse en las labores del hogar ni mucho menos daba lugar a la posibilidad de pensar que alguna pudiera desempeñarse en actividades públicas (p. 92).

En el periodo que sigue a la Independencia, el imperativo era producir buenos ciudadanos que en un futuro contribuyeran a la consolidación de la nación, aún en construcción. En la época posrevolucionaria

Asilo creado en 1810 bajo el impulso del entonces obispo de Nueva Galicia, Juan Cruz Ruiz de Cabañas. Se llamaba entonces Casa de la Caridad y Misericordia, años después adoptaría la denominación de Hospicio Cabañas, en homenaje a su fundador.

3 Aparte de críptica, porque no se acaba de saber qué significa tal expresión, a la vista de los análisis ofrecidos en el libro el uso de esta noción resulta un tanto limitado dado que muchos de los datos proporcionados por la autora son del dominio de la práctica y no sólo del discurso. 
la exigencia será producir hombres "como ejército de futuros ciudadanos, miembros de una sociedad que se imaginaba civilizada y moderna" (p. 150) según los ideales revolucionarios. El país necesitaba, se decía, hombres educados en el autocontrol, la disciplina y la rectitud cívica y moral. Había que educar a los niños en tales valores y ellos a su vez podrían contribuir a alejar a los adultos de los comportamientos considerados perniciosos. Este objetivo implicó ofrecer a esa niñez, en especial a la entregada al Hospicio, "una estricta educación y disciplina basada en la acción" (p. 151). A esto contribuía no sólo la educación formal y el entrenamiento en oficios que se prodigaba en el Cabañas, sino también los festivales y las ceremonias cívicas en las que se resaltaban las figuras de los héroes de la patria e implícitamente se invitaba a los niños — varones - a seguir su ejemplo de intrépida virilidad puesta al servicio de la nación tanto en la gesta de Independencia como en las guerras contra enemigos extranjeros o en la lucha revolucionaria. Asimismo, en la época posterior a la Revolución se cristalizó en el Cabañas la idea del Estado como "instancia educadora del orden social" y protectora de la niñez al hacer de ella el "objeto central del proceso revolucionario en términos de salud, higiene y bienestar social" (p. 280).

Las mujeres tenían un papel preponderante en estas tareas educativas de acuerdo con la creencia de que su naturaleza es dulce y maternal. Las mujeres no tenían derecho de ciudadanía, pero podían ser útiles a la patria - y ser ciudadanas de segunda o de manera indirecta - al procrear y educar a los futuros ciudadanos que le hacían falta al país. En la visión entonces imperante ser mujer entrañaba la predisposición y la capacidad biológicas para ejercer las funciones de madre, aunque también era necesario contar con las cualidades morales para serlo de manera legítima. La cuestión de la naturaleza maternal de toda mujer estuvo en la raíz de diferendos relativos a quién era más idónea para encabezar el Hospicio: una mujer soltera sin hijos biológicos ni compromiso alguno y, por ende, con la absoluta libertad para entregarse a la formación de los niños asilados —que se convertirían simbólicamente en sus hijos-, o una mujer madre de hijos ya independientes. Esta cuestión no se planteaba en los inicios del Hospicio Cabañas porque en estricta concordancia con su origen eclesial fue confiado a las Hermanas de la Caridad de San Vicente de Paúl, ejemplo vivo de la madre ideal: la Virgen María. Esta figura y las monjas son la cristalización de la idea de la maternidad auténtica como construcción simbólica ajena al hecho biológico y, sobre todo, a la sexualidad, esa fuente de peligros de los que las responsables del Hospicio se esforzaban por alejar a las niñas. La madre de Jesús y las monjas son ejemplos cabales de la maternidad como abnegación, entrega y obediencia ciegas de la que eran incapaces las progenitoras de los asilados y para la que se debía educar a las niñas abandonadas. En el discurso se asimilaba a las madres con niños en lo que tocaba a la inocencia. ${ }^{4}$ Los niños habían nacido inocentes y la educación debía servir para mantenerlos en ese estado, mientras que las mujeres que eran buenas madres recuperaban su inocencia por su entrega incondicional a sus hijos y se les incitaba a permanecer en tal estado. Según la autora, las mujeres de clase media se identificaban con este ideal de la maternidad. Había en esto un interés de clase por "universalizar" su visión de la maternidad al presentarla como la legítima.

Fregoso Centeno hace énfasis en la importancia del llamado "orden discursivo de género" en la configuración del Hospicio. Con ello apunta hacia las nítidas diferencias que se establecían en la formación de niñas y niños, además de que casi todas las labores que se realizaban en su interior recaían en mujeres, madres culturales de los niños desamparados que la institución tenía por misión rescatar, formar

Según Sherry B. Ortner (1974), la asimilación de las mujeres con los niños es una constante en todas las culturas. 
y orientar. Con las creencias ligadas al género, algunas prácticas relativas a las diferencias de clase social estaban también presentes en el funcionamiento de la institución en la medida en que ésta acogía, educaba y protegía a niños pobres, al mismo tiempo que ofrecía a los niños ricos la oportunidad de educarse en la caridad al llevar regalos a los asilados y ofrecerse como los modelos de hombres o de mujeres que la nación requería. El Hospicio daba a los ricos bienhechores la posibilidad de mostrarse como cristianos virtuosos y ciudadanos preocupados por la educación y la suerte futura de los niños necesitados.

Las pautas educativas al interior del Cabañas en relación con la maternidad, la infancia, los roles de género, etc., eran un reflejo de las que dominaban en la estructura social en la que estaba inserto este asilo, en la que el modelo de familia nuclear de dominación masculina y la división sexual de las tareas en las familias y en la sociedad eran la norma. Así, en la educación de las niñas "se hacía hincapié, especialmente, en que el futuro era el matrimonio, la maternidad y la familia, por lo que las jóvenes debían poner especial empeño en aprender labores y economía doméstica, disciplina moral e higiene en el cuidado de los menores" (p. 281). Esto obedecía al hecho de que esas menores provenían de espacios sociales considerados anómicos, lo que hacía necesario educarlas en los principios legítimos de la buena formación de una mujer y una futura madre.

Fregoso Centeno muestra también que la historia de los primeros 100 años del Hospicio Cabañas es, hasta cierto punto, la historia del diferendo entre la Iglesia católica y el Estado mexicano respecto de la educación laica. Este asilo es de origen netamente religioso, y no fue sino hasta 1874 , tras la expulsión de las Hermanas de la Caridad, que pasó a manos del Estado. Sin embargo, la disputa en torno a la presencia o no de valores religiosos en la educación de los asilados sobrevivió al cambio de dirección. Al final prevaleció una suerte de cohabitación sin tensiones entre los valores laico-cívicos defendidos por el Estado y los valores religiosos. Esto se explica no tanto por el origen católico de la institución, sino por las fuertes convicciones religiosas de las laicas que la dirigían y de los laicos que aportaban los recursos materiales para su sostenimiento: "el trabajo directo con la 'niñez abandonada' estuvo en manos de un ejército femenino cercano a concepciones religiosas que pudieron impulsarse con libertad, lejos de la mirada social o la opinión pública que funcionaba como censor" (p. 285). Para unas y otros, sólo en la religión se podían encontrar los baremos morales en los que era imperioso a cual más educar a esos niños desamparados y menesterosos de protección y guía. Esto hace ver que, aun en la época posterior a la Revolución Mexicana, la ideología tan llevada y traída del carácter estrictamente laico de la educación impartida por el Estado fue, al menos en el caso de marras, una cuestión más retórica que una práctica cotidiana. En la realidad, se seguía impartiendo enseñanza religiosa en instituciones como el Cabañas con el consentimiento silencioso o cómplice de las autoridades gubernamentales. Tal vez para éstas no fuera tan grave transigir esas cuestiones siempre y cuando se lograra el objetivo de producir cuerpos dóciles y mentes conformes con el orden social dominante y con las representaciones legitimadoras del mismo. D

\section{Bibliografía}

Bock, Gisela y Pat Thane (eds.), 1996, Maternidad y políticas de género: la mujer en los Estados de Bienestar europeos, 1880-1950, Cátedra, Madrid. Kertzer, David, 1993, Sacrified for Honor. Italian Infant Abandonment and the Politics of Reproductive Control, Beacon Press, Boston.

Ortner, Sherry B., 1974, "Is Female to Male as Nature to Culture?", en Michelle Z. Rosaldo y Louis Lamphere (eds.), Woman, Culture, and Society, Stanford University Press, Stanford, pp. 68-87.

Pahl, Ray E., 1984, Divisions of Labour, Blackwell, Oxford. 